\title{
Assessing the Impact of Pregnancy on Sexuality Using the Pregnancy Sexual Response Inventory
}

\author{
Hajrullah Fejza ${ }^{1,2}$, Ejona Icka², Minire Alilaj ${ }^{3}$, Magbule Elezi ${ }^{4}$, Albina Fejza ${ }^{4}$, Liridona Jemini ${ }^{5}$ \\ ${ }^{1}$ Ministry of Health of Kosovo, Prishtina, Kosovo \\ ${ }^{2}$ Institute LIBIDO, Prishtina, Kosovo \\ ${ }^{3}$ Regional Hospital of Ferizaj, Ferixaj, Kosovo \\ ${ }^{4}$ Medical Faculty, University of Prishtina, Prishtina, Kosovo \\ ${ }^{5}$ Faculty of Philosophy, University of Prishtina, Prishtina, Kosovo \\ Email: ^albinafejza@gmail.com
}

How to cite this paper: Fejza, H., Icka, E. Alilaj, M., Elezi, M., Fejza, A. and Jemini, L. (2018) Assessing the Impact of Pregnancy on Sexuality Using the Pregnancy Sexual Response Inventory. Advances in Sexual Medicine, 8, 15-24.

https://doi.org/10.4236/asm.2018.82002

Received: February 18, 2018

Accepted: April 8, 2018

Published: April 11, 2018

Copyright (c) 2018 by authors and Scientific Research Publishing Inc. This work is licensed under the Creative Commons Attribution International License (CC BY 4.0).

http://creativecommons.org/licenses/by/4.0/

cc) (i) Open Access

\begin{abstract}
Introduction: Pregnancy is a state when body undergoes biopsychosocial and hormonal changes which affect pregnant women and her partner. The aim of this study was assessing the changes in sexual life of pregnant women and their partners. Methods: A descriptive cross-sectional study carried out at 8 public hospitals in Kosovo. Mostly, pregnant women in third trimester attending hospitals between July and December 2017 were eligible. The questionnaires have been distributed and supervised by the Kosovo Midwife Association, while have been fulfilled by pregnant women in the delivery room or in their rest rooms. Categorical data were expressed by percentage and comparisons were made by the T-test. Statistical significance was considered as $\mathrm{p}<$ 0.05. Results: Out of 1510 participants, who took part in this study, it is shown that the majority of them were between the age of 18 and 35. Only $7.7 \%$ were under 18 years old. The $66.2 \%$ of the surveyed women have previously planned their pregnancies. The frequency of sexual intercourse per week shows a considerable changing among participants in the study. The number of women who are not satisfied with their sexual lives has increased from $7.9 \%$ before the pregnancy to $18.6 \%$ during pregnancy. The number of women who have never or rarely experienced orgasm has increased from $9.6 \%$ to $16.4 \%$ while the percentage of those who have often experienced orgasm before pregnancy has decreased from $38 \%$ to $22.5 \%$ during pregnancy. From the analyzed parameters only the sexual desire has not undergone changes before and during pregnancy. Moreover, the sexual desire has shown increase, into the option once a day. Conclusion and Recommendation: Apart of sexual desire which remains the same all other parameters have been de-
\end{abstract}


creased during the pregnancy. The role of health professionals in consulting sexual activity problems needs to be improved.

\section{Keywords}

Sexuality, Pregnancy, Pregnancy Sexual Response Inventory

\section{Introduction}

Pregnancy is a state when body undergoes biopsychosocial and hormonal changes which affect pregnant women and her partner. Those changes usually are connected with physical pleasure and sexual activity. Pregnancy and birth mark a very special period in a woman's life. It is a time of physical and psychological changes that commonly impact women's physical wellbeing, mood, relationships and sexuality [1]. These changes included sexual desire, coital frequency, and coital orgasm. They were observed during pregnancy and compared to pre-pregnancy period [2]. Numerous studies have shown that pregnancy has a negative effect on sexual function. However; the data about female sexual function is limited due to a lack of validated instruments and the retrospective design of studies. Different social, cultural and religious beliefs may influence the sexuality of couples in pregnancy [3]. According to published studies it seems that women not always have systematized knowledge about intercourse during pregnancy, which is sometimes associated with unfolded apprehensions. Myths about sex during pregnancy harming fetus and leading to preterm labor or miscarriage are very strong factors releasing fear and leading to avoidance of sexual contact during gestation [4]. Different studies showed that $86 \%-100 \%$ of couples remained sexually active during pregnancy but experienced reduction in sexual activity, especially in the third trimester [5].

This is one of the largest studies about the impact of pregnancy in sexual life using a validated inventory. Many studies concerning sexuality in pregnancy were performed using a different tests and methods. The Pregnancy Sexual Response Inventory (PSRI) is a new validated instrument for evaluating sexuality and sexual activity and related health concerns during pregnancy. It's designed and validated by the group of experts (Cibele VC Rudge et al.) from São Paulo State University, Brazil.

\section{Aim}

The aim of this study was assessing the changes in sexual life of pregnant women and their partners.

\section{Patients and Method}

1) Study design: A descriptive cross-sectional study carried out at 8 public hospitals in Kosovo during the period of five months from July to December 
2017.

2) Study population: Mostly, pregnant women in third trimester attending hospitals between were eligible. The reason for this was to include the whole pregnancy period in the study.

3) Sample size: Study included 1510 pregnant women. Sample size calculation was done based on the data from the Agency of Statistics of Kosovo where is found that the number of births in 2015 was 24,594. Based on this number with the bias margins of $2 \%$ and with the Confidence Interval of $95 \%$, the sample was found to be 2188 participants. This number has been divided into percentage based on hospitals and according to this we have come up with the precise number of women that have to be interviewed in each hospital (Table 1).

4) Exclusion criteria: pregnant women with systemic diseases (diabetes, thyroid dysfunction, heart disease), a sexual partner living separately, a history of drug use, and a diagnosis of psychiatric disorders were excluded from the study.

5) Data collection: The tool was a 38 -item (12 demographic characteristics and 26 sexual behavior or activity) semi-structured PSRI questionnaire which is a new validated instrument for evaluating sexuality and sexual activity and related health concerns during pregnancy. The eight domains of female feelings included: frequency, desire, arousal, orgasm, pleasure, dyspareunia, intercourse initiation, female difficulties and male sexual pleasure assessed by the female view. The questionnaires have been distributed and supervised by the Kosovo Midwife Association, whose members have been trained in advance for the instructions and the help during completion. The questionnaires have been fulfilled by pregnant women in the delivery room or in their rest rooms. The set time for the completion of the questionnaire was thought to be sufficient to be completed within 3 months. After that, 1510 or $69 \%$ of the questionnaires have been in compliance to the criteria and have been added to the database for further analysis.

Approval for the study was given by the local Ethics Committee and an oral

Table 1. Sample size calculation.

\begin{tabular}{cccc}
\hline Hospitals & Births (2015) & \% from total & Sample size \\
\hline Prishtina & 10511 & 42.6 & 932 \\
Vushtri & 506 & 2 & 43 \\
Gjakove & 2115 & 8.6 & 188 \\
Gjilan & 2094 & 8.5 & 186 \\
Mitrovice & 1291 & 5.2 & 115 \\
Peje & 2426 & 9.9 & 217 \\
Prizren & 4020 & 16.6 & 363 \\
Ferizaj & 1631 & 6.6 & 144 \\
Total & 24594 & 100 & 2188 \\
& Bias margin 2\% while CI 95\% & \\
\hline
\end{tabular}


statement of informed consent was obtained from all participants prior to interview.

6) Statistical Analysis: All statistical analyses were performed using the Statistical Package for Social Sciences for Windows Version 20.0 (SPSS 20.0). Categorical data were expressed by percentage and comparisons were made by the T-test. Statistical significance was considered as $\mathrm{p}<0.05$.

\section{Results}

According to the demographic data of 1510 participants, who took part in this study, it is shown that the majority of them were between the age of 18 and 35 . Only $117(7.7 \%)$ were under 18 years old. There were $88.4 \%$ (1335) of the surveyed women in the third trimester of pregnancy. $41.1 \%$ (620) of them have only got one child, whereas 509 (33.7\%) have not got children. It is worth mentioning that $66.2 \%$ (1000) of the surveyed women have previously planned their pregnancies. The use of condoms is not a common phenomenon because $61.1 \%$ (922) of them have declared that they have not used condoms, whereas only 193 $(12.8 \%)$ have stated that they use condoms often or very often (Table 2 ).

The frequency of sexual intercourse per week shows a considerable changing among participants in the study. The number of women who before the pregnancy have not had any sexual intercourse for a week has been $11.3 \%$, in the first trimester this number has increased up to $29.8 \%$, and during the moment of interview has marked $25.2 \%$. In the second option, 1 - 2 times a week there has not

Table 2. Demographic data.

\begin{tabular}{|c|c|c|c|}
\hline Mother's age & $\mathrm{Nr}$ & $\%$ & $\mathrm{p}$ \\
\hline$<18$ & 117 & 7.7 & $<0.05$ \\
\hline $18-25$ & 603 & 39.9 & \\
\hline $26-35$ & 594 & 39.3 & \\
\hline $35+$ & 174 & 11.5 & \\
\hline Gestational age & & & $<0.01$ \\
\hline II trimester & 145 & 9.6 & \\
\hline III trimester & 1335 & 88.4 & \\
\hline Do you have children & & & NS \\
\hline No & 509 & 33.7 & \\
\hline Just one & 620 & 41.1 & \\
\hline Two or more & 377 & 25.0 & \\
\hline Did you plan your pregnancy & & & $<0.05$ \\
\hline Yes & 1000 & 66.2 & \\
\hline No & 501 & 33.2 & \\
\hline Do you use condoms & & & $<0.05$ \\
\hline No & 922 & 61.1 & \\
\hline Yes, but stopped before pregnancy & 386 & 25.6 & \\
\hline Yes, often or very often & 193 & 12.8 & \\
\hline
\end{tabular}


been any significant difference of the state before and during pregnancy. Women who claimed to have sexual intercourse 3 or more times before pregnancy declared a considerable decrease in the first trimester and in the moment of interview (Figure 1).

The number of women who are not satisfied with their sexual lives has increased from $7.9 \%$ (120) before the pregnancy to $18.6 \%$ (281) during pregnancy whilst the number of those who have been satisfied before the pregnancy has decreased during pregnancy, $59.5 \%$ vs. $31.3 \%$. The sexual arousal has also undergone significant statistical changes during the phase of pregnancy. The number of those who had poor sexual intercourse before pregnancy has increased from $8.7 \%$ to $23.2 \%$, whereas the number in percentage of those who have had an excellent sexual arousal before pregnancy has decreased from $31.7 \%$ to $18.8 \%$. From the analyzed parameters only the sexual desire has not undergone changes before and during pregnancy. Moreover, the sexual desire has shown increase, into the option once a day. The orgasm as a sexual cycle response has had changes during pregnancy. The number of women who have never or rarely experienced orgasm has increased from $9.6 \%$ to $16.4 \%$ while the percentage of those who have often experienced orgasm before pregnancy has decreased from $38 \%$ to $22.5 \%$ during pregnancy. Dyspareunia to the participants included in this study did not prove to have important statistical changes comparing to their state before and during the pregnancy. The increase of this phenomenon goes from $30.4 \%$ to $39.5 \%$. The initiation of sexual intercourse is another phenomenon included in PSRI. This study shows a slight increase in number of cases where the partner has persuaded this intercourse from $7.6 \%$ to $8.1 \%$, whereas the number of cases where this intercourse happens impromptu or after stimulation has decreased during pregnancy from $51.3 \%$ ne $45 \%$ (Table 3 ).

PSRI also contains questions that are intertwined with partner's difficulties during sexual intercourse from woman's perspective. There is not any significant change in statistics from the answers for the situation before and during

\section{Frequency of sexual intercourse per week}

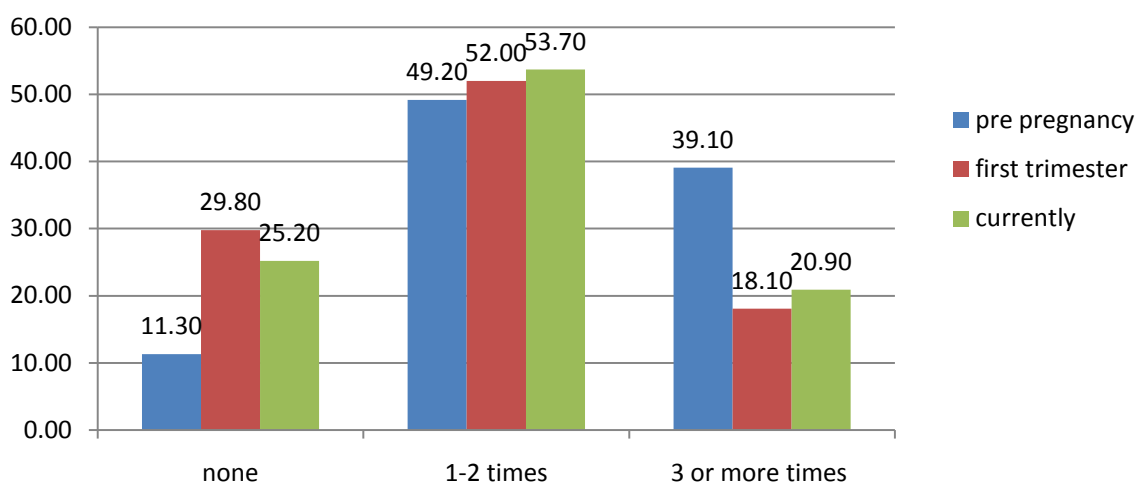

Figure 1. Frequency of sexual intercourse per week. 
Table 3. Satisfaction, arousal, desire, orgasm, pain and initiation of sexual intercourse before and during pregnancy.

\begin{tabular}{|c|c|c|c|}
\hline Satisfaction with sexual life & $\begin{array}{l}\text { Before pregnancy } \\
\mathrm{n}(\%)\end{array}$ & $\begin{array}{c}\text { During pregnancy } \\
\mathrm{n}(\%)\end{array}$ & $\mathrm{p}$ value \\
\hline No & $120(7.9)$ & $281(18.6)$ & \\
\hline Somewhat & $474(31.4)$ & $733(48.5)$ & $<0.05$ \\
\hline Yes & $899(59.5)$ & $473(31.3)$ & \\
\hline \multicolumn{4}{|l|}{ How would you rate your arousal } \\
\hline Poor/very poor & $132(8.7)$ & $350(23.2)$ & \\
\hline Regular & $877(58.1)$ & $853(56.5)$ & $<0.05$ \\
\hline Excellent & $478(31.7)$ & $284(18.8)$ & \\
\hline \multicolumn{4}{|l|}{$\begin{array}{l}\text { How often did you experience } \\
\text { sexual desire }\end{array}$} \\
\hline A few times a week & $544(36.0)$ & $489(32.4)$ & \\
\hline Once a day & $272(18.0)$ & $288(19.1)$ & NS \\
\hline Other (depending on the occasion ) & $671(44.4)$ & $723(47.9)$ & \\
\hline \multicolumn{4}{|l|}{ How often did you achieve orgasm } \\
\hline Never/rarely & $145(9.6)$ & $248(16.4)$ & \\
\hline Sometimes & $764(50.6)$ & $891(59.0)$ & $<0.05$ \\
\hline Often or very often & $574(38.0)$ & $340(22.5)$ & \\
\hline \multicolumn{4}{|l|}{ Pain during sexual intercourse } \\
\hline Yes & $459(30.4)$ & $596(39.5)$ & NS \\
\hline No & $1022(67.7)$ & $886(58.7)$ & \\
\hline \multicolumn{4}{|l|}{ The initiation of intercourse } \\
\hline Forced, without any desire & $115(7.6)$ & $123(8.1)$ & \\
\hline Partner usually made the first move & $584(38.7)$ & $665(44.0)$ & NS \\
\hline $\begin{array}{c}\text { Spontaneously or spontaneously } \\
\text { with stimuli }\end{array}$ & $775(51.3)$ & $687(45.5)$ & \\
\hline
\end{tabular}

pregnancy. Women in $18.3 \%$ of cases think that the partner had sexual obstacles before the pregnancy and this number is slightly increased to $24 \%$ during pregnancy (Figure 2).

\section{Discussion}

This study is a rare one in which PSRI questionnaire has been used. It is the only one designed and structured test to assess specifically the impact of pregnancy in the sexual life between women and their partners. Then, the sample chosen with up to 1500 participants, distinguishes this study from the others. The PSRI was developed over a series of stages, including pre-selection of the initial items, pretesting on volunteer pregnant women and then validation of the internal consistency reliability and content validity by a panel of expert consultants. The results from the present investigation demonstrated that the PSRI has good internal consistency and reliability over its entire scale (Cronbach's $\alpha=0.79$ ) and is suitable for use in assessing sexual function during pregnancy in obstetric 


\section{Do you think you partner had any sexual difficulties}

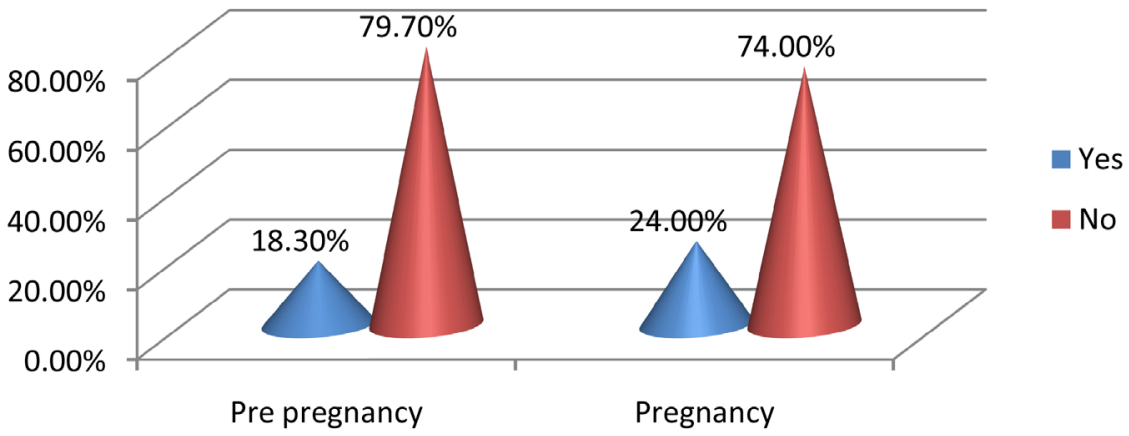

Figure 2. Partners sexual difficulties. $\mathrm{p}<0.005$.

clinical samples [1].

Psychological aspects and physiological changes in pregnant women strongly correlate with sexual function during that specific period. It is believed that sexual function diminishes over the course of pregnancy. Before conceiving women mostly had intercourses 1 - 2 times during the week (53.7\%).

Only 1 in 4 respondents had intercourse 1 to 3 times in a month [4]. The frequency of sexual intercourses usually changes at the beginning of the pregnancy and stabilizes in the first trimester and again declines in the third trimester. Jelena Isajeva et al. in their study founded that $52.6 \%(\mathrm{n}=41)$ had frequent sexual intercourse during the first trimester, $24.4 \%(\mathrm{n}=19)$ had it during the second trimester and only a small amount of the women had it during the third trimester. The majority of the authors indicate a decrease in the frequency of sexual intercourse during pregnancy [5]. In this study an increase in the number of women who did not have any sexual intercourse during a week in the first quarter can be noticed. On the other hand, the number of cases where women claim that they have had more than 3 sexual intercourses per week is evidently decreased in the first and the third quarter. According to a study conducted in Taiwan the majority of the women stopped engaging in coital activities during pregnancy [6] Indications for abstaining from intercourse during pregnancy: vaginal bleeding, placenta previa premature dilatation of the cervix, rupture of the membranes, history of premature delivery and multiple pregnancy [7]. Pauleta et al. determined that fear of sexual intercourse in the first trimester was pointed out by $23.4 \%$ of 199 respondents [8].

Women often wonder about the safety of sexual intercourse while pregnant and also seem not to discuss it openly with their caregivers [9]. The situation changes again in the most challenging third trimester. Traditional sexual acts become more difficult and less frequent because of physical aches and obstacles, such as decreased desire, lubrication and sexual satisfaction. The level of emotional stress and anxiety related to the possible complications increases as the time of delivery approaches. According to the Iranian study by Torkestani et al., the most prevalent reasons for the decreasing frequency of intercourse during 
pregnancy was fear of abortion (39.45\%), declining libido in the second trimester $(26.28 \%)$, and fear of membrane rupture in the third trimester $(19.3 \%)$. The frequency of intercourse was highest in the first trimester (36.8\% had intercourse once a week), than in the second trimester (32.9\% had intercourse once a month), and third trimester (49.7\% reported no sexual intercourse) [10]. The results of the study by Aslan G et al. showed that sexual functions are significantly decreased during pregnancy and worsen as the pregnancy progresses [11]. The rate of sexual satisfaction declined as pregnancy progressed, particularly during the third trimester. The sexual functioning declines as pregnancy progresses compared with pre-pregnancy [12].

The number of women participants in our study, who have not been satisfied with their sexual lives before pregnancy, has been $7.9 \%$. This number has shown increase to $18.6 \%$ while the number of women that have been satisfied with their sexual lives before the pregnancy has evidently been decreased during pregnancy from $59.5 \%$ to $31.3 \%$, which shows that pregnancy affects negatively to sexual satisfaction. Different scholars have come up to different results related to this phenomenon. Sexual satisfaction was unchanged in $48.4 \%$ of the subjects and decreased in $27.7 \%$, [8]. Dissatisfaction with sexual life increased from 0.7 to 9.9\% [4]. Folasade Adenike Bello for Nigeria, reported reduction in sexual satisfaction and frequency of orgasms (similar to findings by other authors [13].

According to the literature, the sexual arousal hasn't been widely studied so far. In our study the percentage of women who have had poor/very poor arousal has increased from $8.7 \%$ to $23.2 \%$, while the percentage of those who had excellent arousal before pregnancy has decrease from $31.7 \%$ to $18.8 \%$.

According to most authors, sexual function worsens throughout pregnancy, with desire being the most affected phase of the sexual response. A perceived tendency toward improvement of the sexual pattern occurs during the second trimester [14]. In our study, we could not prove any significant differences related to sexual desires before and during pregnancy. Moreover, the number of participants in this study has shown a slight increase related to sexual desires during pregnancy. Pauleta et al. also founded that sexual desire is reported to be unchanged in $38.8 \%$ and decreased in $32.5 \%(\mathrm{p}=0.196)$ of the population [8] The most common reason for the abandonment of sexual activities during gestation is the hypoactive sexual desire disorder, i.e. the lack or absence of sexual needs [4]. The pregnant women at each trimester reported a gradual and significant decrease in sexual desire $(\mathrm{p}<0.05)$ and coital frequency [2].

A substantial number of women have notable problem in reaching orgasm. In our study the number of women who have never or rarely had orgasm is increased during pregnancy from $9.6 \%$ to $16.4 \%$. Pregnancy has obviously worsened the reach of orgasms to women who before pregnancy have claimed to have often or very often orgasms (38\% vs. $22.5 \%)$. The percentages of pregnant women who had never had an orgasm in the first trimester, the second trimester and the third trimester were $25 \%, 18 \%$, and $28 \%$ respectively. Trimester comparison showed that orgasms were statistically increased in the second trimester 
however, orgasms were significantly decreased in all trimesters compared to the pre-pregnancy period [3]. The change in orgasmic rate was not statistically significant. Most of the women in each trimester reported a decrease in orgasmic rate. The women in the second trimester had the highest percentage of decreasing orgasmic rate, although it was not statistically significant [2].

Şule Gökyildiz determined that pregnant women felt more pain during the coitus as the pregnancy progressed. In our study, we could not find any important statistical differences related to the pain during sexual intercourse. Libido and sexual satisfaction may also be negatively affected by a woman's self-perception of decreased attractiveness. Typically, as pregnancy progresses, there is a decrease in the achievement of orgasm and sexual satisfaction, and an increase in painful intercourse [15].

Sexual intercourse is mostly initiated by men, both in pre-pregnancy and pregnancy periods. There were no statistically significant differences in the rate of initiation of sexual intercourse before pregnancy, between trimesters or during pregnancy [3]. From the study it has been revealed that in only approximately $50 \%$ of the cases the initiation has happened impromptu or after a proper stimulation. In the other cases, the partner has persuaded initiation $7.6 \%$ to $8 \%$, or the partner has insisted. Limitations about this study were the new questionnaire without sufficient data by other scientific papers, the lack of similar studies within the same culture and knowledge and bias during the questionnaire fulfillment.

\section{Conclusion and Recommendation}

After those interpretations we can conclude that apart of sexual desire which remains the same all other parameters have been decreased during the pregnancy. The role of health professionals in consulting sexual activity problems needs to be improved.

\section{References}

[1] Rudge, C.V., et al. (2009) Design and Validity of a Questionnaire to Assess Sexuality in Pregnant Women. Reproductive Health, 6, 12. https://doi.org/10.1186/1742-4755-6-12

[2] Senkumwong, N., Chaovisitsaree, S., Rugpao, S., Chandrawongse, W. and Yanunto, S. (2006) The Changes of Sexuality in Thai Women during Pregnancy. Journal of the Medical Association of Thailand, 89, S124-S129.

[3] Efe, H., Bozkurt, M., Sahin, L., Mutlu, M.F., Api, M. and Çetin, A. (2014) The Effects of Pregnancy on the Sexual Life of Turkish Women. Proceedings in Obstetrics and Gynecology, 4, 5.

[4] Staruch, M., Kucharczyk, A., Zawadzka, K., Wielgos, M. and Szymusik, I. (2017) Sexual Activity during Pregnancy. Act Nerv Super Rediviva, 59, 23-28.

[5] Isajeva, J., Šilkūnas, M., Drąsutienè, G.S. and Bartkevičienè, D. (2012) Features of the Sexual Life during Pregnancy. Acta Medica Lituanica, 19, 67-74.

https://doi.org/10.6001/actamedica.v19i2.2312 
[6] Liu, H.L., Hsu, P. and Chen, K.H. (2013) Sexual Activity during Pregnancy in Taiwan. A Qualitative Study. The Journal of Sexual Medicine, 1, 54-61. https://doi.org/10.1002/sm2.13

[7] Brown, C., Bradford, J., et al. (2008) Sex and Sexuality in Pregnancy. Global Library of Women's Medicine. https://doi.org/10.3843/GLOWM.10111

[8] Pauleta, J.R., Pereira, N.M. and Graca, L.M. (2010) Sexuality during Pregnancy. The Journal of Sexual Medicine, 7, 136-142. https://doi.org/10.1111/j.1743-6109.2009.01538.x

[9] Kontoyannis, M., Katsetos, C. and Panagopoulos, P. (2012) Sexual Intercourse during Pregnancy. Health Science Journal, 6, 82-87.

[10] Torkestani, F., Hadavand, Sh., Khodashenase, Z., Besharat, S., Davati, A., Karimi, Z. and Zafarghandi, N. (2012) Frequency and Perception of Sexual Activity during Pregnancy in Iranian Couples. International Journal of Fertility \& Sterility, 6, 107-110.

[11] Aslan, G., Aslan, D., Kizilyar, A., Ispahi, C. and Esen, A. (2005) A Prospective Analysis of Sexual Functions during Pregnancy. International Journal of Impotence Research, 17, 154-157. https://doi.org/10.1038/sj.ijir.3901288

[12] Gokyildiz, S. and Beji, N.K. (2005) The Effects of Pregnancy on Sexual Life. Journal of Sex and Marital Therapy, 31, 201-215. https://doi.org/10.1080/00926230590513410

[13] Bello, F.A., Olayemi, O., Aimakhu, C.O. and Adekunle, A.O. (2011) Effect of Pregnancy and Childbirth on Sexuality of Women in Ibadan, Nigeria. ISRN Obstetrics and Gynecology, 2011, Article ID: 856586. https://doi.org/10.5402/2011/856586

[14] Santiago, L.R.S., et al. (2013) Impact of Pregnancy on the Sex Life of Women: State of the Art. International Journal of Clinical Medicine, 4, 257-264. https://doi.org/10.4236/ijcm.2013.45045

[15] Jones, C., Chan, C. and Farine, D. (2011) Sex in Pregnancy. CMAJ, 183, 815-818. https://doi.org/10.1503/cmaj.091580 